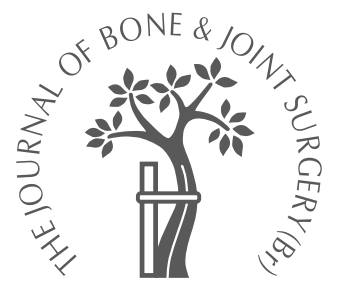

A. S. Montgomery, R. Birch, A. Malone

From the Royal National Orthopaedic Hospital, Stanmore, England

A. S. Montgomery, MRCS, Senior House Officer R. Birch, FRCS, Professor A. Malone, MRCS Specialist Registrar Peripheral Nerve Injury Unit, The Royal National Orthopaedic Hospital, Brockley Hill, Stanmore, Middlesex HA7 4LP, UK.

Correspondence should be sent to $\mathrm{Mr}$ A. S.

Montgomery; e-mail: asm@doctors.org.uk

(C)2005 British Editorial Society of Bone and Joint Surgery doi:10.1302/0301-620X.87B3. $15828 \$ 2.00$

$J$ Bone Joint Surg [Br] 2005;87-B:410-11.

Received 12 July 2004; Accepted after revision 13 August 2004

\title{
Sciatic neurostenalgia: caused by total hip arthroplasty, cured by late neurolysis
}

\author{
We describe a patient with a painful sciatic neuropathy after total hip arthroplasty. \\ Treatment was confined to neuroleptic and analgesic agents until neurolysis at seven years \\ abolished pain and restored function.
}

\section{Case report}

A 57-year-old woman had a cemented total hip replacement for primary osteoarthritis in 1996 through a posterior approach. An epidural block was not used. Post-operatively she had an intense and focal pain in the buttock radiating down the leg, with a cold tingling in the foot. The pain was disabling and prevented her from sleeping, and walking. There was deep bruising around the buttock, and complete paralysis of the foot. During the post-operative period, there was much discharge of blood from the wound requiring several transfusions. Subsequently gabapentin only partially relieved the pain, but at such a high dose that it rendered her incapable of working as a lecturer.

The nerve palsy was complete for the first two months after which there was a gradual and partial recovery. She sought relief of the pain by attending five orthopaedic units in the UK. The palsy was not investigated by neurophysiological methods.

She was reviewed in our unit seven years after the operation. The pain remained severe, affecting sleep, and every aspect of daily life. She had not returned to work. On examination, there was neither wasting of the muscles nor fixed deformity. There was no obvious sudomotor or vasomotor dysfunction in the foot. A strong and painful Tinel's sign was elicited by percussion over the sciatic nerve at the level of the neck of the femur. Light touch anywhere on the foot provoked intolerable pain (mechanical allodynia). There was loss of sensation in the deep division of the common peroneal nerve. The power of muscles innervated by the tibial nerve appeared normal. The power of muscles innervated by the common peroneal nerve were graded as $2 / 5$ on the MRC scale. Knee and ankle reflexes were present but diminished. Radiological examination revealed a well placed total hip replacement, with no extrusion of cement.

Nerve conduction studies showed normal sensory conduction (sural nerve), and preserved motor conduction (peroneal and tibial nerves).

Electromyography demonstrated that fibrillation potentials were confined to the tibialis anterior muscle. These were associated with a reduced recruitment of neurones and an excess of high amplitude polyphasic motor units. These findings suggested that the sciatic palsy was predominantly one of conduction block with an element of degenerative lesion (axonopathy). ${ }^{1}$

The nerve was explored to establish a diagnosis and to relieve pain. An oblique incision was used, splitting gluteus maximus and preserving the neurovascular bundle. There was no evidence of neuroma or direct damage. There was no disturbance of the epineural vessels, confirming that this was not an intraneural lesion. Tight adhesions tethered the nerve behind the level of the neck of femur over a length of $4 \mathrm{~cm}$. There was demonstrable tugging of the nerve on movement of the adjacent joints. After external neurolysis, nerve stimulation proximal to the lesion revealed strong conduction distally for both divisions of the sciatic nerve. Two days later the patient was discharged pain free with a full neurological recovery. She was reviewed six months after the operation. Full neurological function and pain relief were maintained and she had returned to work. We felt that nerve conduction studies were not indicated as recovery had been complete.

\section{Discussion}

Neurostenalgia, ${ }^{2}$ a common pain syndrome, reflects a persisting lesion of the nerve which is 
anatomically intact, and has the potential for physiological expression. It is provoked by entrapment, distortion or ischaemia. Removal of the cause relieves pain, and restores neurological function.

The main indication for exploration was the persistence of severe pain within the distribution of the nerve. A focal lesion was indicated by the presence of a strong Tinel's sign. Neurophysiological investigations predicted that the nerve was largely intact and the lesion predominantly a conduction block with an element of axonal degeneration. We believe that an extraneural haematoma was the original cause. There had been extensive local post-operative haemorrhage with marked bruising of the buttock and upper thigh. The nerve was not stretched, nor was it narrowed at the level of the lesion, suggesting that neither traction nor crushing were significant provoking factors. Haematoma would have led to adventitial fibrosis, tethering and immobilisation of the nerve, and resulting pain. Neurostenalgia indicates that the provoking agent is still active, and that the indication for exploration of the nerve is strong.

A deep and painful neuropathy incurred during surgery requires investigation. Secondary exploration of the nerve should be considered.

Painful neuropathy is not a diagnosis, and referral of such patients to a pain clinic is inappropriate until a diag- nosis has been made. Prolonged conduction block, ${ }^{3,4}$ a common lesion in orthopaedic practice, occurs when nerves are entrapped in fractures, ${ }^{5}$ adventitial fibrosis, or callus, or become ischaemic through compression in a swollen compartment, or by stretching of the nerve over an expanding haematoma.

In some cases there is spontaneous resolution. Lord Nelson ${ }^{6}$ suffered from constant stump pain following the amputation of his arm. Many years later there was sudden relief of pain when a ligature, which included the median nerve, discharged spontaneously through the wound.

No benefits in any form have been received or will be received from a commercial party related directly or indirectly to the subject of this article.

\section{References}

1. Smith SJM. The role of neurophysiological investigation in traumatic brachial plexus lesions in adults and children. J Hand Surg [Br] 1996;21B:145-70.

2. Birch R, Bonney G, Wynn Parry CB, eds. Surgical disorders of peripheral nerves. London: Churchill Livingstone, 1998.

3. Fowler TJ, Dunta G, Gilliatt RW. Recovery of nerve conduction after a pneumatic tourniquet: observations in the hind limb of a baboon. J Neurol Neurosurg Psychiatry 1972;35:638-47.

4. Gilliat RW. Acute compression block. In: Sumner AJ, ed. Physiology of peripheral nerve disease. Philadelphia: W.B. Saunders Co, 1980:287-315.

5. Birch R, St Claire Strange FG. A new type of peripheral nerve lesion. J Bone Joint Surg [Br] 1990;72-B:312-13.

6. Carola 0. Nelson. London: Hodder and Stoddart, 1947:268-9. 